\title{
Pruritus and Renal Failure
}

\author{
Timothy G. Berger, MD," and Martin Steinhoff, MD, PhD ${ }^{*,+}$
}

\begin{abstract}
Patients with renal failure, usually end-stage renal disease (ESRD), commonly are afflicted by severe pruritus. The pathogenesis of ESRD pruritus is unknown, but improving the quality of dialysis can reduce the prevalence and severity of ESRD pruritus. Topical and systemic agents as well as broadband ultraviolet phototherapy can be extremely beneficial. Gabapentin has been recently discovered as an effective agent for the patient with ESRD pruritus. Kappa opiate agonists are promising new therapeutic options. Semin Cutan Med Surg 30:99-100 @ 2011 Published by Elsevier Inc.
\end{abstract}

$\mathrm{P}$ ruritus is a common symptom in patients with end-stage renal disease (ESRD). In older series, up to $90 \%$ of patients were afflicted with pruritus, but now between $20 \%$ and $50 \%$ are affected. ${ }^{1-3}$ Pruritus occurs independent of the cause of the ESRD, and patients on both peritoneal and hemodialysis experience pruritus at similar rates. All races, both genders and all ages can develop ESRD pruritus. ${ }^{4}$ Nephrologists have recognized and documented significant impact of itch on ESRD patients' quality of life. In addition, pruritus is an independent predictor of increased mortality, probably because of effect on a patient's quality of sleep.

The pathogenic basis of pruritus in renal failure is unknown. The renal failure must be severe to be associated with pruritus. The resolution of itch, albeit slowly in some cases, after renal transplantation suggests that a factor normally removed by the kidney but not effectively removed during dialysis is playing a role. Xerosis is common in patients with ESRD and may contribute to pruritus. ESRD pruritus is associated with elevated C-reactive protein and other inflammatory cytokines, suggesting there is an inflammatory component in this form of pruritus. The abnormalities of calcium metabolism that occur in the setting of ESRD may lead to formation of calcium phosphate crystals in the skin. These crystals may stimulate itch receptors. As in hepatic pruritus,

*Department of Dermatology, University of California San Francisco, San Francisco, CA.

$\dagger$ Department of Surgery, University of California San Francisco, San Francisco, CA.

Dr. Berger has nothing to disclose and no conflict of interests to report. Dr. Steinhoff has performed consultancy services for which he received compensation for Galderma, Merck, Sanofi-Aventis and Regeneron. On behalf of Dr. Steinhoff, his institution has received financial gifts from Maruho (Japan), and research was supported by ZymoGenetics, L'Oreal and Galderma.

Address reprint requests to Timothy G. Berger, MD, Department of Dermatology, University of California San Francisco, 1701 Divisadero Street, Room 341, San Francisco, CA 94143. E-mail: bergert@derm.ucsf.edu endogenous opioids may be important in mediating the itch associated with ESRD. Once chronic pruritus has occurred, there may be secondary changes in nerves in the skin and perhaps the central nervous system which enhance the perception/sensation of itch (central sensitization).

The clinical characteristics of ESRD pruritus are variable. ${ }^{1}$ The pruritus may be constant or intermittent. The back is the most commonly affected area, but arms, head, and abdomen are also commonly affected. Excoriations with no primary lesions, and sparing of the butterfly area of the back are typical. Patients with ESRD, especially if attributable to diabetes mellitus, frequently develop keratotic nodules that on biopsy show a perforating disorder. These represent prurigo nodules and are a marker for severe and long-term pruritus.

The therapy for renal pruritus is often rewarding because the dermatologist has numerous options, some of which are usually effective. Treatment begins with topical agents. Treatment of xerosis with moisturization and gentle skin care can be quite beneficial. ${ }^{5}$ The addition of soothing topicals containing menthol or pramoxine can be tried. ${ }^{6}$ Topical capsaicin can also be beneficial for patients with localized pruritus. Topical tacrolimus dramatically reduced pruritus by $80 \%$ in one study of patients with ESRD pruritus, but the vehicle gave a similar result. ${ }^{7}$ For localized pruritus, this could be considered as an option, but for widespread itch, systemic absorption and cost are limitations.

Standard first- and second-generation antihistamines are usually of limited value. However, doxepin $10 \mathrm{mg}$ once or twice daily has been shown effective. ${ }^{8}$ Blood levels can be monitored enhancing safety. Mirtazepine $15-30 \mathrm{mg} / \mathrm{d}$ is another option. Both montelukast and cromolyn sodium, agents used in allergic disorders, have shown efficacy in ESRD pruritus. ${ }^{9,10}$

Adequate and effective dialysis is critical in alleviating pruritus in ESRD. ${ }^{10}$ Controlling calcium and phosphorus seems to be particularly important. ${ }^{11}$ In addition, treating the underlying iron deficiency may alleviate itch. ${ }^{12}$ 
The administration of $300 \mathrm{mg}$ of gabapentin after each dialysis has been shown in multiple studies to improve ESRD pruritus. ${ }^{13}$ The response to treatment, although not universal, is usually durable, and when effective is a very safe new addition for the treatment of ESRD pruritus. Pregabalin can be similarly effective. ${ }^{14}$

Ultraviolet B (UVB) phototherapy, especially broadband UVB, is frequently effective for ESRD pruritus. ${ }^{15} \mathrm{NB}-\mathrm{UVB}$ and UVA alone do not appear as effective. Starting at three times per week and reducing to maintenance once or twice weekly can often control the pruritus.

The standard opiate antagonists naltrexone and butorphanol can be tried but have not been universally beneficial. Nalfurafine, a kappa agonist, demonstrated modest improvement and is a potential new option for treatment of ESRD pruritus. $^{16}$

In refractory patients, novel approaches may be useful. The administration of $1 \mathrm{mg}$ of ganisetron orally twice a day can be effective, but another serotonin type 3 receptor antagonist, ondansetron, is ineffective. ${ }^{17}$ The administration of $600 \mathrm{mg}$ of pentoxyfilline once after each dialysis, although poorly tolerated by some patients, was reasonably effective in a small series. ${ }^{2}$ Thalidomide at a dose of $100 \mathrm{mg}$ daily has reduced pruritus rapidly in one series and should be considered in refractory patients, especially those with prurigo nodules. ${ }^{18}$ In the most severely affected patients, $5 \mathrm{mg}$ of nicergoline intravenously during dialysis can be tried. ${ }^{3}$ Acupuncture and other physical modalities may provide benefit. ${ }^{1,19}$

\section{References}

1. Patel TS, Freedman BI, Yosipovitch G: An update on pruritus associated with CKD. Am J Kidney Dis 50:11-20, 2007

2. Mettang M, Weisshaar E: Pruritus: Control of itch in patients undergoing dialysis. Skin Ther Lett 15:1-5, 2010

3. Feramisco JD, Berger TG, Steinhoff M: Innovative management of pruritus. Dermatol Clin 28:467-478, 2010

4. Senturk N, Ozkaya O, Aytekin S, et al: Characteristics of pruritus in children on peritoneal dialysis. Nephron Clin Pract 109:c168-c172, 2008

5. Yosipovitch G, Duque MI, Patel TS, et al: Skin barrier structure and function and their relationship to pruritus in end-stage renal disease. Nephrol Dial Transplant 22:3268-3272, 2007

6. Young TA, Patel TS, Camacho F, et al: A pramoxine-based anti-itch lotion is more effective than a control lotion for the treatment of uremic pruritus in adult hemodialysis patients. J Dermatol Treat 20:76-81, 2009

7. Duque MI, Yosipovitch G, Fleischer AB Jr, et al: Lack of efficacy of tacrolimus ointment $0.1 \%$ for treatment of hemodialysis-related pruritus: A randomized, double-blind, vehicle-controlled study. J Am Acad Dermatol 52:519-521, 2005

8. Pour-Reza-Gholi F, Nasrollahi A, Firouzan A, et al: Low-dose doxepin for treatment of pruritus in patients on hemodialysis. Iran J Kidney Dis 1:34-37, 2007

9. Nasrollahi AR, Miladipour A, Ghanei E, et al: Montelukast for treatment of refractory pruritus in patients on hemodialysis. Iran J Kidney Dis 1:73-77, 2007

10. Vessal G, Sagheb MM, Shilian S, et al: Effect of oral cromolyn sodium on CKD-associated pruritus and serum tryptase level: A double-blind placebo-controlled study. Nephrol Dial Transplant 25:1541-1547, 2010

11. Chen ZJ, Cao G, Tang WX, et al: A randomized controlled trial of high-permeability haemodialysis against conventional haemodialysis in the treatment of uraemic pruritus. Clin Exp Dermatol 34:679-683, 2009

12. Noordzij M, Boeschoten EW, Bos WJ, et al; For the NECOSAD Study Group: Disturbed mineral metabolism is associated with muscle and skin complaints in a prospective cohort of dialysis patients. Nephrol Dial Transplant 22:2944-2949, 2007

13. Jenkins P: A common cause of pruritus in dialysis patients. Am J Kidney Dis 51:345, 2008 author reply: 345-346

14. Vila T, Gommer J, Scates AC: Role of gabapentin in the treatment of uremic pruritus. Ann Pharmacother 42:1080-1084, 2008

15. Hsu MM, Yang CC: Uraemic pruritus responsive to broadband ultraviolet (UV) B therapy does not readily respond to narrowband UVB therapy. Br J Dermatol 149:888-889, 2003

16. Kumagai H, Ebata T, Takamori K, et al: Effect of a novel kappa-receptor agonist, nalfurafine hydrochloride, on severe itch in 337 haemodialysis patients: A phase III, randomized, double-blind, placebo-controlled study. Nephrol Dial Transplant 25:1251-1257, 2010

17. Layegh P, Mojahedi MJ, Malekshah PE, et al: Effect of oral granisetron in uremic pruritus. Indian J Dermatol Venereol Leprol 73:231-234, 2007

18. Silva SR, Viana PC, Lugon NV, et al: Thalidomide for the treatment of uremic pruritus: A crossover randomized double-blind trial. Nephron 67:270-273, 1994

19. Hsu MC, Chen HW, Hwu YJ, et al: Effects of thermal therapy on uremic pruritus and biochemical parameters in patients having haemodialysis. J Adv Nurs 65:2397-2408, 2009 